\title{
An Asporogenous Variant of Streptomyces griseus
}

\author{
By J. CHRISTINE APPLEBY \\ Research Department, Bacteriology Division, Boots Pure Drug Co. Ltd., Nottingham-
}

SUMMARY: A non-sporulating form of Streptomyces griseus occurred spontaneously in culture. It appears to be a true variant of the species. Ultra-violet irradiation stimulated the variation. The variant was readily isolated on media containing relatively large amounts of organic nitrogen, but capable of propagation upon very simple media. The fact that the variant can be stabilized throws some doubt upon the validity of the present basis for classification of the actinomycetes.

It is now well known that Streptomyces griseus, in common with other actinomycetes, produces in culture media variants showing distinct cultural and biochemical features. Of these a grey and a white colony variant (see Pl. 1, figs. 1, 4) have been described (Schatz \& Waksman, 1945). The former owes its colour to an abundant pigmented aerial mycelium, a feature which is associated with streptomycin production, whereas the white variant is less actively sporulating and produces insignificant amounts of streptomycin. A third colony type was also described by Schatz \& Waksman which was non-sporulating and did not form streptomycin. This reverted spontaneously to the parent form.

As a result of examination of a large number of species in the Actinomyces group, Afanasiev (1937) found that in the pathogenic but not in the saprophytic types the amount of aerial mycelium produced was greatly influenced by the nitrogen content of the medium. Other workers (Waksman, 1919; Erikson, 1947) have under certain conditions obtained cultures of species of actinomycetes, which were devoid of any aerial mycelium, and this is usually considered to be a transitory condition, occurring particularly on media rich in organic nitrogen. However, sporadic appearances of an asporogenous form of Str. griseus in cultures of the purified grey variant grown on simple liquid media threw some doubt upon this conception. Its appearances could not be attributed either to an initial excess of organic nitrogen or to enrichment of the medium by autolytic products of the associated grey mycelium.

\section{Isolation of the asporogenous form of Streptomyces griseus}

Examination of a large number of strains of Str. griseus showed that the asporogenous form could be obtained and propagated on a variety of media. Its frequency was markedly increased by ultra-violet irradiation of Str. griseus spores. It represents a variation from the normal type as abrupt, discontinuous and complete as the white variant, and the cultures isolated are very stable. The same medium may give rise to normal grey, white and asporogenous growths, the last two appearing sometimes as sectors in grey colonies. It would therefore appear that the asporogenous form of Str. griseus may represent a mutation rather than a temporary response to a particular culture medium. 
The asporogenous variants were purified by plating and, unlike those of Schatz \& Waksman, were found to be very stable. Morphologically they consist of undifferentiated vegetative mycelium composed of hyphae of very uniform diameter, which tend in old cultures to break up into segments resembling oidia. Though they will grow on a wide variety of media the frequency of their appearance is governed to some extent both by the amount and the state of the nitrogen present. For example, freeze-dried cultures of the grey variant gave rise to permanently asporogenous colonies in the first generation on media containing peptone or glycine, but not on Czapek (sodium nitrate) agar or ammonium sulphate agar (Schatz \& Waksman, 1945), and the proportion of the asporogenous type increased with increased amounts of peptone or glycine. The asporogenous variant comprised $12.6 \%$ of the total colonies from a purified grey variant on a medium containing $1 \%$ peptone and $0.5 \%$ meat extract, but less than $1 \%$ on a medium with $0.5 \%$ glycine as the only source of nitrogen.

Though the asporogenous variant could not be isolated from grey cultures on Czapek or ammonium sulphate agar, it could be propagated upon these media, and was in fact able to grow, though poorly, on a synthetic medium containing washed agar and no added nitrogen. With peptone, glycine or ammonium sulphate as the nitrogen source the variant grew well. With from 0.5 to $1 \%$ peptone (Pl. 1, fig. 2) growth was relatively rapid and profuse, and single colonies reached a diameter of $30 \mathrm{~mm}$., when they lost their characteristic tenacious consistency and became friable, growing upwards in vertical ridges with marked pigment production; $1 \%$ of glycine or ammonium sulphate produced a similar effect, but without pigment. With comparable amounts of sodium nitrate or with decreased amounts of glycine or ammonium sulphate, growth was much more scanty (Pl. 1, fig. 3).

\section{Stability of the asporogenous variant}

Reversion by purified cultures of the asporogenous variant does not occur readily, and was never found, during 5 months' observations, on media where growth was either abundant or very poor. Cultures have been kept for many weeks on peptone and glycine media, and on a nitrogen-free medium, without any detectable macroscopic or microscopic evidence of spore formation (Pl. 1, fig. 6). Partial reversion occurred most readily on media containing an inorganic nitrogen source in such concentration that growth was neither profuse nor too sparse. Thus, where the nitrogen content of the medium consisted of $0.005-0.05 \%$ of ammonium sulphate or sodium nitrate a white powdery surface film developed on prolonged incubation, often appearing first as papillae or in concentric rings (Pl. 1, fig. 5). Subcultures from these colonies invariably reproduced the asporogenous form, with a varying proportion of feebly sporulating colonies resembling a poorly developed white variant. It was not possible to reproduce a parent grey variant on any medium. It is conceivable that even this feeble tendency to reversion might be eliminated by selection.

It therefore appears that the asporogenous growth of Str. griseus represents 
a true variant of the species, possessing greater stability than the parent form. The presence or absence of aerial mycelium has been used as a major criterion in classification of the actinomycetes, inability to produce this being a diagnostic feature of the Actinomyces group II $b$ (Ørskov, 1923) and of the genus Nocardia (Waksman \& Henrici, 1943). Consideration of the fundamental relationship between asporogenous and sporulating types and of the capacity of sporogenic forms to give rise to those permanently asporogenous might perhaps help to eliminate some of the present uncertainty in the nomenclature of this group of organisms, and place their systematic relationships upon a surer foundation.

The author wishes to express her thanks to Sir J. Drummond, F.R.S., and to Mr C. E. Coulthard for their helpful interest in this work; and to Mr P. H. Johnson for the photographs.

\section{REFERENCES}

Afanasiev, M. M. (1937). Comparative physiology of Actinomyces in relation to potato scab. Bull. Neb. agric. Exp. Sta. no. 92, p. 1.

ErIKson, D. (1947). Differentiation of the vegetative and sporogenous phases of the actinomycetes. 2. Factors affecting the development of aerial mycelium. J.gen. Microbiol. 1, 45.

ØRSkov, J. (1923). Investigations into the Morphology of the Ray Fungi. Copenhagen: Levin and Munksgaard.

Schatz, A. \& Waksman, S. A. (1945). Strain specificity and production of antibiotic substances. IV. Variations among actinomycetes, with special reference to Actinomyces griseus. Proc. nat. Acad. Sci., Wash., 31, 129.

Waksman, S. A. (1919). Cultural studies of species of Actinomyces. Soil Sci. 8, 71.

Waksman, S. A. \& Henrici, A. T. (1943). The nomenclature and classification of the actinomycetes. $J$. Bact. 46, 337 .

\section{EXPLANATION OF PLATE}

Fig. 1. Grey variant of Streptomyces griseus; 10 days old; starch ammonium sulphate agar. $\times 1 \frac{1}{2}$.

Fig. 2. Asporogenous variant; 8 days old; peptone agar. $\times 5$.

Fig. 3. Asporogenous variant; 8 days old; $0.5 \%$ glycine agar. $\times 5$.

Fig. 4. Grey and white variants; 3 weeks old; starch ammonium sulphate agar. $\times 1 \frac{1}{2}$.

Fig. 5. Asporogenous variant; 6 weeks old; starch ammonium sulphate agar; natural size, showing scanty production of aerial mycelium in concentric rings.

Fig. 6. Asporogenous variant; 6 weeks old; $0.5 \%$ glycine agar. $\times 1 \frac{1}{2}$. 
Journal of General Microbiology, Vol. 2, No. 1
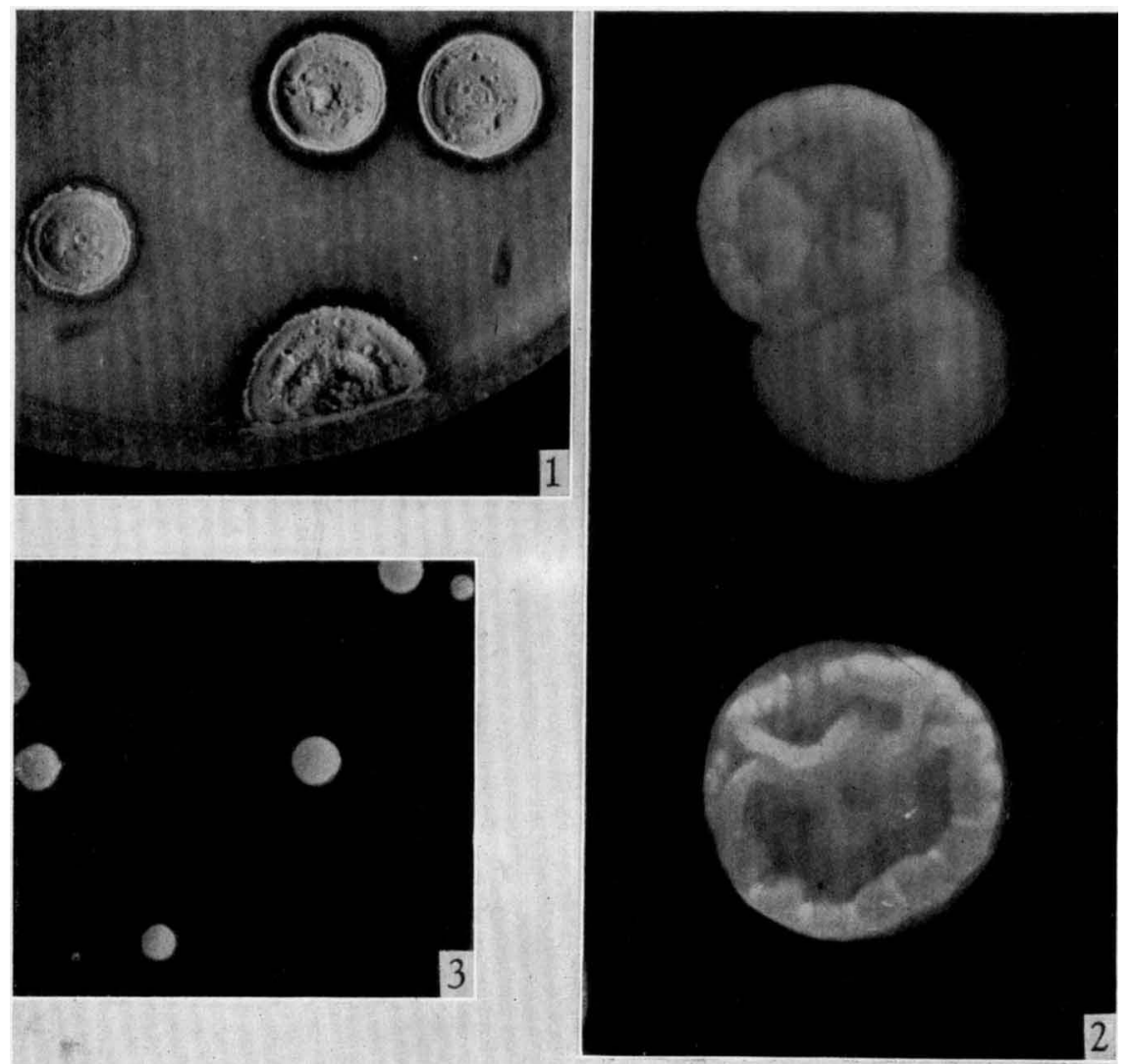

2

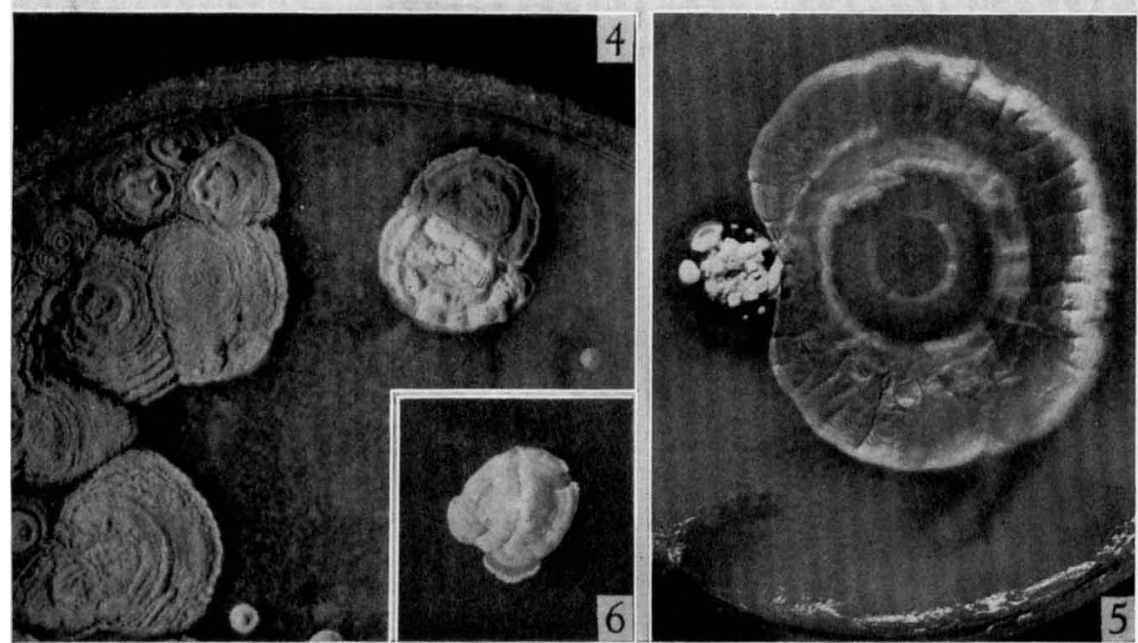

Figs. 1-6

J. C. Appleby-An asporogenots variant of streptomyues griseus. Plate 1 